\title{
Evaluation of the efficacy of a novel radical neck dissection preserving the external jugular vein, greater auricular nerve, and deep branches of the cervical nerve
}

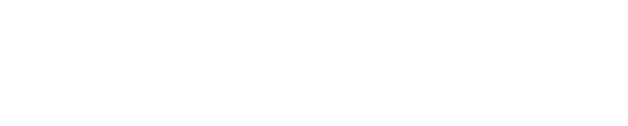

Yadong $\mathrm{Li}$

Jinsong Zhang

Kai Yang

Department of Oral and Maxillofacial Surgery, The First Affiliated Hospital of Chongqing Medical University, Chongqing, People's Republic of China
Correspondence: Kai Yang Department of Oral and Maxillofacial Surgery, The First Affiliated Hospital of Chongqing Medical University, No I, Youyi Road,Yuzhong District, Chongqing 400016 ,

People's Republic of China

Tel +862389012569

Fax +862389012569

Email cqfyyk@hotmail.com
Background: Conventional radical neck dissection often causes a variety of complications. Although the dissection method has been improved by retaining some tissues to reduce complications, the incomplete dissection may cause recurrence of disease. In the present study, we developed a novel radical neck dissection, which preserves the external jugular vein, the greater auricular nerve, and the deep branches of the cervical nerve, to effectively reduce complications and subsequently, to promote the postoperative survival quality.

Methods: A total of 100 cases of radical neck dissection were retrospectively analyzed to evaluate the efficacy, rate of complication, and postoperative dysfunction of patients treated with the novel radical neck dissection. Data analysis was performed using the Chi-square test.

Results: Compared with conventional radical neck dissection, the novel radical neck dissection could significantly reduce complications and promote postoperative survival quality. Particularly, the preservation of the external jugular vein reduced the surgical risk (ie, intracranial hypertension) and complications (eg, facial edema, dizziness, headache). Preservation of the deep branches of the cervical nerve and greater auricular nerve resulted in relatively ideal postoperative functions of the shoulders and ear skin sensory function $(P<0.05)$, while the two types of dissection procedures showed no differences in the recurrence rate $(P>0.05)$.

Conclusion: Our novel radical neck dissection procedure could effectively reduce the complications of intracranial hypertension, shoulder dysfunction, and ear sensory disturbances. It can be used as a regular surgical approach for oral carcinoma radical neck dissection.

Keywords: oral cancer, head and neck cancer, squamous cell carcinoma, survival quality, neck dissection, recurrence

\section{Introduction}

Squamous cell carcinoma accounts for a majority of the cases of oral and maxillofacial malignancies. ${ }^{1}$ Due to its frequent daily activities, the oral and maxillofacial region has a loose structure and dense vascular and lymphatic distributions. Hence, oral and maxillofacial squamous cell carcinoma has a high rate of regional lymph node metastasis ${ }^{2}$ and has been an important research topic for surgeons. ${ }^{3}$ The systemic metastases of oral and maxillofacial squamous cell carcinoma always occur via ipsilateral lymphatic channels. When the carcinoma reaches the neck, the metastasis can stay in the neck for some time before further invasion, which provides an ideal time for treatment. Therefore, to promote the efficacy of oral carcinoma treatment, the regional lymph node metastasis should be treated in addition to the primary cancer. In 1906, Crile $^{4}$ reported the first case of radical neck dissection 
(RND) aimed at cervical lymph node metastases, which was later improved and standardized by Martin et al, ${ }^{5}$ to better suppress cervical lymph node metastases, and has been widely recognized as the most classic means to cure oral carcinoma. ${ }^{6}$

Neck dissection is defined as the complete dissection of lymph nodes and lymphatic vessels within the lymphatic-refluxrelated neck region. The lymph nodes are distributed throughout the neck, and the lymphatic vessels are too small to be isolated. Hence, all other tissues associated to the lymphoid tissues, including the fatty connective tissues, muscles, and unimportant blood vessels and nerves should be removed, which may easily cause complications. For instance, the dissection of the internal jugular vein can result in acute intracranial blood flow disorders, headache, or even death; the dissection of the accessory nerve can cause postoperative shoulder syndrome; the dissection of the great auricular nerve can induce ear paresthesia. All these complications can greatly affect the life quality of the patients. ${ }^{7}$ Therefore, in the past half century, researchers have made great efforts to explore the range and content of neck dissection and have developed a number of improved dissection procedures, such as preservation of the internal jugular vein and accessory nerve. ${ }^{8}$ However, although these improved procedures could effectively reduce complications, the retained lymphoid tissues increased the risk of recurrence.

The primary purpose for the treatment of malignancies is complete radical dissection, followed by safety, and preservation. ${ }^{9}$ Based on this principle, we improved the conventional neck dissection. Considering the anatomic structure of the neck lymphatic reflux of oral carcinoma, the intracranial venous reflux channel following jugular vein disconnection, and the redundancy of the deep branches of the cervical plexus after accessory nerve resection, we chose to perform RND with preservation of the external jugular vein, greater auricular nerve, and deep branches of the cervical nerve. As radical and functional neck dissection have been well defined, we named this improved procedure novel radical neck dissection (NRND). First of all, NRND has the same dissection range and content as the conventional RND, so it is a radical dissection. Second, the external jugular vein is preserved to retain the reflux channel of the maxillofacial and intracranial veins, such that facial edema and intracranial complications can be reduced. Third, when the accessory nerve is dissected, the $\mathrm{C} 2-\mathrm{C} 4$ deep branches of the cervical plexus are preserved to innervate the trapezius. Lastly, the great auricular nerve is not involved in the cervical lymph node metastasis of oral carcinoma, and thus, the preservation of this nerve can reduce auricular numbness. This is the first report of NRND. In this study, we evaluated the efficacy, safety, and complication of NRND. Our study provides reference for the wide application of NRND.

\section{General patient information}

A total of 100 oral carcinoma patients admitted to our hospital between January 2001 and December 2006 were verified by pathological examination. The 100 patients included 61 males and 39 females, with an average age of 51.1 years (31-60 years) and a median age of 52 years. The 100 oral carcinoma cases included 48 cases of tongue cancer, 32 cases of buccal cancer, 14 cases of mouth floor carcinoma, and six cases of lower gum cancer. The pretreatment TNM classification and clinical stage were determined based on the Union for International Cancer Control (UICC) standards (2002 edition). The patients were randomly divided into two groups, one treated with unilateral RND and the other treated with unilateral NRND (Table 1).

\section{Surgery \\ RND}

One group of 48 patients was treated with conventional RND, with dissection of the internal jugular vein, greater auricular nerve, and accessory nerve. ${ }^{5}$ (Figure 1 ).

\section{NRND}

The other group of 52 patients was treated with NRND, with preservation of the external jugular vein, greater auricular nerve, and deep branches of the cervical nerve

Table I General information of the patients involved in this study

\begin{tabular}{lll}
\hline & RND & NRND \\
\hline $\begin{array}{l}\text { Case number } \\
\text { Gender }\end{array}$ & 48 & 52 \\
Male & 30 & 31 \\
$\quad$ Female & 18 & 21 \\
Position & & \\
$\quad$ Tongue & 22 & 26 \\
Cheek & 14 & 18 \\
Mouth floor & 8 & 6 \\
$\quad$ Lower gum & 4 & 2 \\
Clinical stage & 13 & 14 \\
III & 35 & 38 \\
IV & & \\
$\mathrm{cN}$ & 16 & 16 \\
$\mathrm{~N}_{1}$ & 32 & 36 \\
$\mathrm{~N}_{2}$ & & \\
\hline
\end{tabular}

Note: $N_{1}=$ metastasis in a single ipsilateral lymph node, $3 \mathrm{~cm}$ or less in greatest dimension; $\mathrm{N}_{2}$ = metastasis in a single ipsilateral lymph node more than $3 \mathrm{~cm}$ but not more than $6 \mathrm{~cm}$ in greatest dimension, or metastasis in multiple ipsilateral lymph nodes, none more than $6 \mathrm{~cm}$ in greatest dimension, or metastasis in bilateral or contralateral nodes, no more than $6 \mathrm{~cm}$ in greatest dimension.

Abbreviations: $\mathrm{cN}$, clinical $\mathrm{N}$ stage; RND, radical neck dissection; NRND, novel radical neck dissection. 


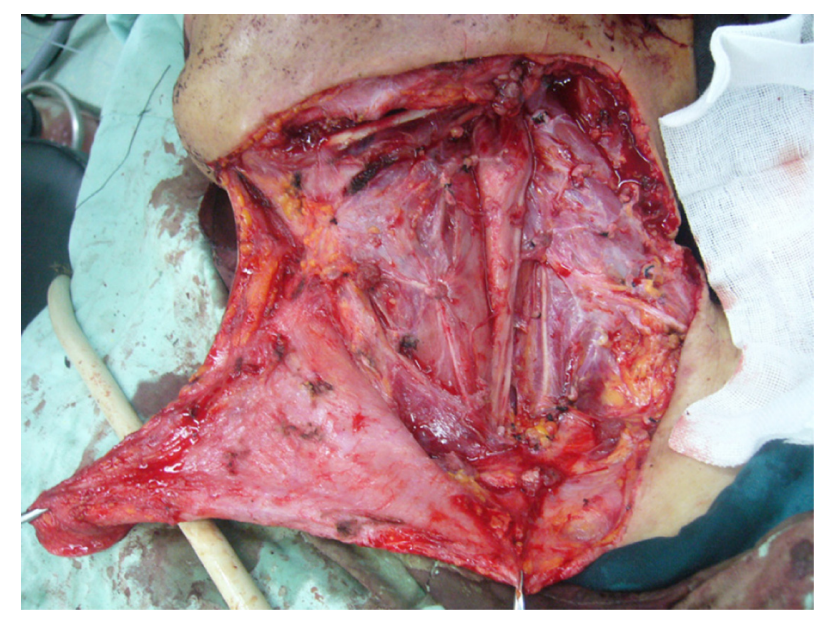

Figure I The patient was treated with conventional RND. Abbreviation: RND, radical neck dissection.

(Figures 2 and 3). A rectangular incision was made, and the platysma flap was revealed in a standard manner to expose the intact external jugular vein. The external jugular vein was isolated along the shallow surface of the sternocleidomastoid muscle until the deep cervical fascia of the collarbone. The great auricular nerve, which pierces the central posterior border of the sternocleidomastoid and winds along the sternocleidomastoid, was also observed. The external jugular vein and great auricular nerve were isolated and well protected. Conventional RND was conducted. Due to the uncertainty about the junction point of the external and internal jugular veins, the internal jugular vein was cut off at the segment distal to the junction point. At the posterior triangle, the great auricular nerve was protected from the initial segment in the cervical plexus, and the cervical accessory nerve and segments 2 , 3 , and 4 of the cervical spinal nerve were isolated. The accessory nerve was cut off at its upper junction with the

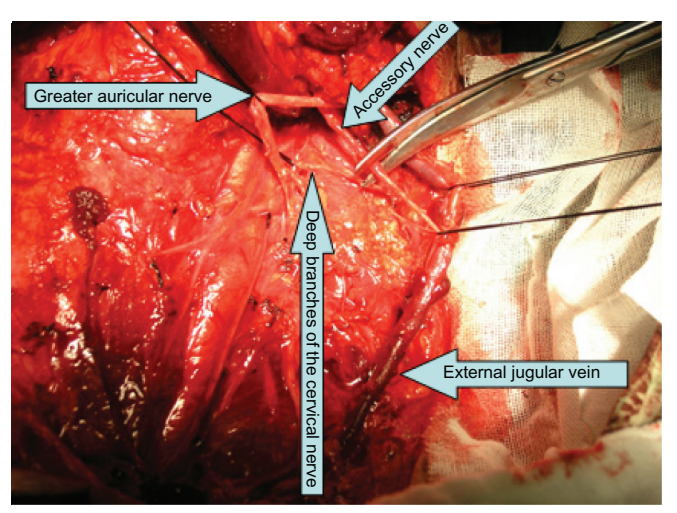

Figure 2 The patient was treated with NRND before the accessory nerve was dissected.

Abbreviation: NRND, novel radical neck dissection.

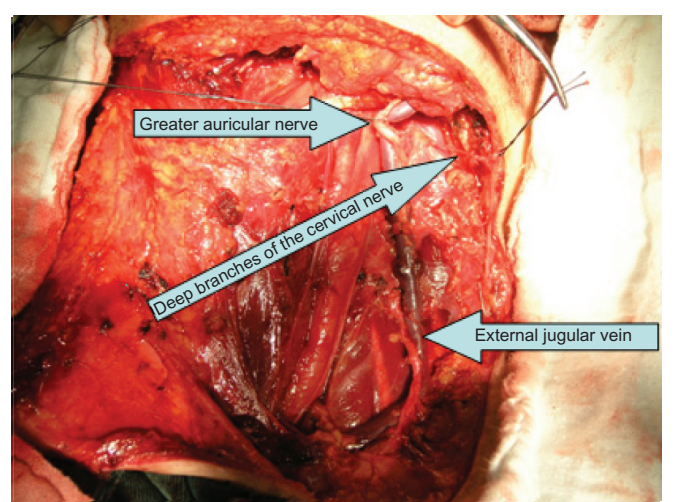

Figure 3 The patient was treated with NRND after the accessory nerve was dissected. Abbreviation: NRND, novel radical neck dissection.

deep cervical plexus branches. The deep branches of the cervical plexus extending into the deep trapezius were well preserved. The subsequent surgical procedure was identical to conventional RND.

\section{Indicators and methods}

Monitoring of facial and intracranial venous reflux The postsurgical maxillofacial edema and regression time, as well as dizziness and headache, were monitored.

\section{Monitoring of the function of the great auricular nerve}

At 6 months postsurgery, the auricle and ear skin sensory function of the patients was monitored. Briefly, the surgicalside skin was stimulated using a disinfected probe, and the other-side skin was used as the control. The feeling of the patients was classified into three categories including numbness, hypoesthesia, and normal, to understand the preservation of the ear skin sensory function of the patients.

\section{Monitoring of shoulder symptoms and functions}

At 6 months postsurgery, the shoulder pain and upper-limb movement of the patients were monitored. The shoulder symptoms were graded as follows: (1) Severe degree: the shoulder and upper arm feel severe pain which affects sleep, and the angle between the trunk midline and the laterally rising upper limb is less than 60 degrees; (2) Moderate degree: the pain is obvious but does not affect sleep, and the angle is between 60 and 90 degrees but the parietooccipital area cannot be reached even if the elbow is bent; and (3) Mild degree: there is no obvious pain, and the angle is larger than 90 degrees, but it is still difficult to reach the parietooccipital area. 


\section{Monitoring of the postoperative survival}

The number of cases of postsurgical cervical lymph node metastasis diagnosed by pathological examination was recorded. The rate of cervical lymph node recurrence identified during follow up was also analyzed. All patients received a 5-year follow up.

\section{Data analysis}

Data were analyzed using $t$-test, Chi-square test, rank sum test, and the Fisher's exact test. $P<0.05$ was determined as statistically significant.

\section{Results}

\section{Facial and intracranial venous reflux}

All patients had Phase I incision healing. The facial and intracranial venous reflux was evaluated as follows: 43 (89.6\%) conventional RND patients and 20 (38.5\%) NRND patients showed apparent maxillofacial edema $(P<0.05)$. The average edema regression time was $4.4 \pm 0.3$ days for the RND group and $3.1 \pm 0.4$ days for the NRND group $(P<0.05)$. In all, $38(79.2 \%)$ RND patients and seven (13.5\%) NRND patients showed varying degrees of dizziness and headache $(P<0.05)$ (Table 2).

\section{Function of the great auricular nerve}

The ear skin sensory function, based on self-feeling, was reviewed 6 months after the surgery. The RND patients often reported auricular and posterior ear skin numbness or hypoesthesia, while the NRND patients usually reported normal feeling (Table 3).

\section{Shoulder symptoms and functions}

The review at 6 months postsurgery showed that the NRND patients had significantly better shoulder function than did the RND patients (Table 4).

Table 2 Facial edema, dizziness, and headache

\begin{tabular}{lllll}
\hline & RND & NRND & $\begin{array}{l}\text { Statistical } \\
\text { value }\end{array}$ & P-value \\
\hline Facial edema & 43 & 20 & 27.98 & $<0.01$ \\
$\begin{array}{l}\text { Edema regression } \\
\text { time (d) }\end{array}$ & $4.4 \pm 0.3$ & $3.1 \pm 0.4$ & 91.92 & $<0.01$ \\
$\begin{array}{l}\text { Dizziness and } \\
\text { headache }\end{array}$ & 38 & 7 & 43.53 & $<0.01$ \\
\hline
\end{tabular}

Notes: The facial edema, dizziness, and headache were analyzed using Chi-square test. The edema regression time was analyzed using $t$-test. The difference was considered significant when $P<0$.05. There was significant difference in facial edema, edema regression time, dizziness, and headache between RND and NRND.

Abbreviations: NRND, novel radical neck dissection; RND, radical neck dissection.

\section{Cervical lymph node metastasis rate and recurrence rate}

At the time of surgery, 45 out of 48 (93.7\%) RND patients and 47 out of $52(90.4 \%)$ NRND patients were diagnosed with cervical lymph node metastasis $(P<0.05)$. During the 5 -year follow up, there were four cases (8.33\%) of recurrence in the RND group and four cases (7.69\%) in the NRND group $(P<0.05)$ (Table 5).

\section{Discussion}

Neck dissection is a preferential method to treat the cervical lymph node metastasis of oral carcinoma. ${ }^{10,11}$ However, in conventional RND, the dissection of the accessory nerve and great auricular nerve can easily result in long-term complications, including pinna and surrounding skin numbness, and neck and shoulder pain associated with motor dysfunction. Moreover, the dissection of the internal and external jugular veins during RND often causes maxillofacial edema due to the poor face venous reflux, or causes intracranial hypertension and subsequently dizziness and headache, ${ }^{12}$ or even occasionally induces death. Therefore, it has been an important research topic for surgeons to achieve both radical surgery and least complications. ${ }^{13-17}$ During the past century, the original destructive radical neck dissection has been improved to maximally preserve the function., ${ }^{5,15,18}$ The constantly increased life quality requirement is the internal driving force for the continuous development of neck dissection. Importantly, progress in the research on oral cancer cervical lymph node metastasis and the anatomical structure of the neck, as well as the advancement in clinical experience, provides technical support for the improvement of neck dissection.

Based on the past basic and clinical research, ${ }^{19-22}$ we developed the NRND procedure, based on the conventional RND but distinctly characterized by the preservation of the external jugular vein, greater auricular nerve, and deep branches of the cervical nerve, to maximally reduce complications.

\section{Intracranial blood reflux disorder and external jugular vein preservation}

In the neck, lymphatic channels and the internal jugular vein accompany each other and have the same flow directions. When oral squamous cell carcinoma metastasis occurs along the neck lymphatic channels, the metastasis is largely distributed around the internal jugular vein and may invade the vein. Hence, the internal jugular vein is dissected for the purpose of complete radical dissection. However, this can 
Table 3 Sensitivity of the skin of the auricle at 6 months after operation

\begin{tabular}{|c|c|c|c|c|c|c|}
\hline & \multirow{2}{*}{$\begin{array}{l}\text { Case } \\
\text { number }\end{array}$} & \multicolumn{3}{|c|}{ Sensitivity of the skin of the auricle } & \multirow{2}{*}{$\begin{array}{l}\text { Statistical } \\
\text { value }\end{array}$} & \multirow[t]{2}{*}{$P$-value } \\
\hline & & Normal & Hypoesthesia & Numbness & & \\
\hline RND & 48 & 3 & 31 & 14 & 17.44 & $<0.01$ \\
\hline NRND & 52 & 31 & 20 & I & & \\
\hline
\end{tabular}

Notes: The analysis was performed using rank sum test and revealed significant difference. The difference was considered significant when $P<0.05$.

Abbreviations: NRND, novel radical neck dissection; RND, radical neck dissection.

cause a variety of severe complications, including extensive intracranial venous stasis-induced cerebral edema and intracranial hypertension, which in turn may result in brain damage and blindness. In some patients with contralateral vascular malformations, these complications may even induce death. ${ }^{23}$

Past anatomic research has suggested that the internal jugular vein is the main route of the intracranial blood reflux, and the spinal venous plexus and pharyngeal esophageal venous plexus are the main collateral circulation channels. However, the total cross-sectional area of the compensatory channels is still significantly smaller than that of the internal jugular vein, ${ }^{24}$ and it would take a long time to establish a complete compensation. Hence, the external jugular vein can play an important role in the compensatory intracranial venous reflux. ${ }^{25}$ In the conventional RND, both the internal and external jugular veins are dissected, which frequently causes intracranial complications. In the previous improvements of neck resection, the internal jugular vein was usually preserved to avoid intracranial complications. However, this strategy contravenes the principle of complete radical dissection and increases the risk of recurrence. In the present study, we, for the first time, preserved the external jugular vein while dissecting the internal jugular vein, by which not only was the dissection radical, but also, the intracranial and face venous reflux channels were preserved. Our results indicated that compared with the conventional RND, our NRND not only significantly reduced the incidence and regression time of facial edema, but also reduced the incidence of dizziness and headache $(P<0.05)$. These observations confirmed that preservation of the external jugular vein could reduce the risks of intracranial hypertension and surgery, as well as the postoperative care difficulty. The cervical fascia shallow layer, where the external jugular vein is located, is rarely invaded by tumors. Hence, the preservation of the external jugular vein should not affect the radical degree of the surgery.

\section{Shoulder syndrome and preservation of the deep branches of the cervical plexus}

Shoulder syndrome, ${ }^{26}$ one of the common severe complications of conventional RND, has the symptoms of shoulder pain, shoulder droop, and limitations in shoulder and arm activities. Shoulder syndrome is mainly caused by the dissection of the trapezius-innervating accessory nerve, which not only causes trapezius paralysis and atrophy, but which can also oppress the deep shoulder muscles and rhomboid muscle.

Functional RND preserving the accessory nerve can largely avoid the shoulder syndrome. However, the accessory lymph cluster is distributed along the accessory nerve, and thus, preserving the accessory nerve significantly affects the radical degree of the surgery. Autograft not only would inevitably sacrifice the donor nerve, but can also increase the complexity of the surgery and subsequently lead to a reduced success rate and prolonged recovery. Previous anatomic research has suggested that the trapezius muscle was innervated by both the accessory nerve and deep cervical plexus branches. Stacey et a $\mathrm{a}^{19}$ carried out postmortem study and found that the nerve fibers in the $\mathrm{C} 2-\mathrm{C} 4$ ventral motor root of the cervical plexus can also innervate the trapezius muscle. We found that patients who had the deep cervical plexus branches preserved only occasionally showed shoulder pain and did not show obvious shoulder droop. At 6 months postsurgery, these patients had upper-limb outreach beyond the horizontal line and could complete general movements

Table 4 Shoulder function at I year after operation

\begin{tabular}{|c|c|c|c|c|c|c|}
\hline & \multirow{2}{*}{$\begin{array}{l}\text { Case } \\
\text { number }\end{array}$} & \multicolumn{3}{|c|}{ Shoulder syndrome and function } & \multirow[t]{2}{*}{ Statistical value } & \multirow[t]{2}{*}{$P$-value } \\
\hline & & Slight & Moderate & Severe & & \\
\hline RND & 48 & 10 & 24 & 14 & 5.29 & $<0.01$ \\
\hline NRND & 52 & 46 & 6 & 0 & & \\
\hline
\end{tabular}

Notes: The analysis was performed using rank sum test and revealed significant difference. The difference was considered significant when $P<0.05$. 
Table 5 Comparison of the postoperative cervical recurrence rate

\begin{tabular}{|c|c|c|c|c|}
\hline & RND & NRND & $\begin{array}{l}\text { Statistical } \\
\text { value }\end{array}$ & $P$-value \\
\hline $\begin{array}{l}\text { Case number of cervical } \\
\text { lymph node metastasis }\end{array}$ & 45 & 47 & $0.384 I$ & $>0.05$ \\
\hline $\begin{array}{l}\text { Cervical lymph node } \\
\text { recurrence rate }\end{array}$ & $8.33 \%$ & $7.69 \%$ & 0.0139 & $>0.05$ \\
\hline
\end{tabular}

Notes: The case number of cervical lymph node metastasis was analyzed using Chi-square test. The cervical lymph node recurrence rate was analyzed using the Fisher's exact test. The difference was considered significant when $P<0.05$. There was no significant difference in the case number of cervical lymph node metastasis and the cervical lymph node recurrence rate between RND and NRND.

Abbreviations: NRND, novel radical neck dissection; RND, radical neck dissection.

but had difficulties in holding up the arm and shrugging. In sharp contrast, the patients without preservation of the deep branches of the cervical plexus had obvious shoulder droop, shoulder pain and numbness, and sometimes insomnia. At 6 months postsurgery, these patients did not have upper limb outreach beyond the horizontal line and showed difficulties in rotation and adduction, as well as reduced working ability.

In the conventional RND, both the accessory nerve and the cervical plexus are dissected, which in turn causes shoulder syndrome. To diminish this complication, the conventional RND was modified to preserve the accessory nerve. However, previous attempts to reduce the radical degree resulted in an increased risk of recurrence. In the present study, we preserved the deep $\mathrm{C} 2-\mathrm{C} 4$ cervical plexus branches while dissecting the accessory nerve, by which not only was the radical degree not reduced, but the trapezius innervation and function was preserved. Our results indicated that compared with the conventional RND, the NRND significantly relieved the shoulder syndrome and retained the shoulder function $(P<0.05)$. These results indicated that the deep cervical plexus branches can partly compensate for the functional loss of the accessory nerve. Furthermore, it was safe to retain the cervical plexus due to the scarce distribution of peripheral lymphoid tissues. The NRND did not affect the radical degree, complexity, or time period of the surgery and subsequently promoted the life quality of the patients.

\section{Preservation of the great auricular nerve}

In conventional RND, the dissection of the great auricular nerve usually results in long-term auricular numbness or, sometimes, even local frostbite. Although the great auricular nerve was not usually preserved in previous improvements of RND, this nerve is rarely related to the cervical lymph node metastasis. However, in most cases, preservation of the great auricular nerve did not affect the radical degree of the surgery. ${ }^{27}$ Hence, we attempted to preserve the great auricular nerve when conducting RND surgery. Our results indicated that compared with conventional RND, NRND could significantly retain the auricular skin sensitivity $(P<0.05)$ and reduce the incidence of postsurgical auricular numbness, and subsequently promoted the life quality of the patients.

The primary goal of neck dissection is the complete radical dissection. Our results showed that the two groups of patients had a similar cervical lymph node metastasis case number and a similar recurrence rate $(P<0.05)$. These observations indicated that unlike past improved RND, which showed a reduced radical degree due to the preservation of some tissues, our NRND did not reduce the radical degree of the conventional RND.

In summary, the NRND, preserving the external jugular vein, greater auricular nerve, and deep branches of the cervical nerve, has overcome the limitations of the conventional and previously improved RND procedures. With the radical degree unaffected, the NRND diminished the postsurgical complications of intracranial hypertension, shoulder dysfunction, and auricular numbness. Therefore, NRND can be used as a regular surgical approach for oral carcinoma RND.

\section{Acknowledgments}

This study was partly supported by Chongqing Medical University (Grant No XBYB2007020), the Natural Science Foundation Project of CQ CSTC (Grant No cstc2012jjA10039), and the Chongqing Municipal Health Bureau (Grant No 2011-2-013, 2012-2-049).

\section{Disclosure}

The authors report no conflicts of interest in this work.

\section{References}

1. Zheng JW, Qiu WL, Zhang ZY. Combined and sequential treatment of oral and maxillofacial malignancies: an evolving concept and clinical protocol. Chin Med J (Engl). 2008;121(19):1945-1952.

2. Robbins KT, Medina JE, Wolfe GT, Levine PA, Sessions RB, Pruet CW. Standardizing neck dissection terminology. Official report of the Academy's Committee for Head and Neck Surgery and Oncology. Arch Otolaryngol Head Neck Surg. 1991;117(6):601-605.

3. Brockton NT, Klimowicz AC, Bose P, et al. High stromal carbonic anhydrase IX expression is associated with nodal metastasis and decreased survival in patients with surgically-treated oral cavity squamous cell carcinoma. Oral Oncol. 2012;48(7):615-622.

4. Crile G. Excision of cancer of the head and neck. With special reference to the plan of dissection based on one hundred and thirty-two operations. JAMA. 1987;258(22):3286-3293.

5. Martin H, Del Valle B, Ehrlich H, Cahan WG. Neck dissection. Cancer. 1951;4(3):441-499.

6. Liao CT, Hsueh C, Lee LY, et al. Neck dissection field and lymph node density predict prognosis in patients with oral cavity cancer and pathological node metastases treated with adjuvant therapy. Oral Oncol. 2012;48(4):329-336 
7. Licad JV, Sison DR, Yusi GM. Problems in radical neck dissection. Philipp J Cancer. 1962;4:167-171.

8. André P, Laccourreye H, Haguet JF, Beauvillain de Montreuil C, Henin JM, Aubert JD. Comparaison des résultats carcinologiques à long terme entre les évidements cervicaux radicaux et conservateurs. [Comparison of long-term carcinologic results between radical and conservative cervical surgery.] Ann Otolaryngol Chir Cervicofac. 1975;92(3):113-126. French.

9. Mourouzis C, Pratt C, Brennan PA. Squamous cell carcinoma of the maxillary gingiva, alveolus, and hard palate: is there a need for elective neck dissection? Br J Oral Maxillofac Surg. 2010;48(5):345-348.

10. Rigual NR, Wiseman SM. Neck dissection: current concepts and future directions. Surg Oncol Clin NAm. 2004;13(1):151-166.

11. Chummun S, McLean NR, Ragbir M. Surgical education: neck dissection. Br J Plast Surg. 2004;57(7):610-623.

12. Ward MJ, Faris C, Upile T, Patel NN. Ophthalmoplegia secondary to raised intracranial pressure after unilateral neck dissection with internal jugular vein sacrifice. Head Neck. 2011;33(4):587-590.

13. Bocca E, Pignataro O. A conservation technique in radical neck dissection. Ann Otol Rhinol Laryngol. 1967;76(5):975-987.

14. Jesse RH, Ballantyne AJ, Larson D. Radical or modified neck dissection: a therapeutic dilemma. Am J Surg. 1978;136(4):516-519.

15. Bocca E, Pignataro O, Oldini C, Cappa C. Functional neck dissection: an evaluation and review of 843 cases. Laryngoscope. 1984;94(7): 942-945.

16. Pellitteri PK, Robbins KT, Neuman T. Expanded application of selective neck dissection with regard to nodal status. Head Neck. 1997;19(4): 260-265.

17. Crean SJ, Hoffman A, Potts J, Fardy MJ. Reduction of occult metastatic disease by extension of the supraomohyoid neck dissection to include level IV. Head Neck. 2003;25(9):758-762.
18. Friedman M, Lim JW, Dickey W, et al. Quantification of lymph nodes in selective neck dissection. Laryngoscope. 1999;109(3):368-370.

19. Stacey RJ, O'Leary ST, Hamlyn PJ. The innervation of the trapezius muscle: a cervical motor supply. J Craniomaxillofac Surg. 1995;23(4): 250-251.

20. McKinney P, Gottlieb J. The relationship of the great auricular nerve to the superficial musculoaponeurotic system. Ann Plast Surg. 1985; 14(4):310-314.

21. Fisher CB, Mattox DE, Zinreich JS. Patency of the internal jugular vein after functional neck dissection. Laryngoscope. 1988;98(9):923-927.

22. Nori S, Soo KC, Green RF, Strong EW, Miodownik S. Utilization of intraoperative electroneurography to understand the innervation of the trapezius muscle. Muscle Nerve. 1997;20(3):279-285.

23. Rolffs J, Schmelzle R. Serious cerebral complications following unilateral ligation of the internal jugular vein. Review of the literature and a case report. J Maxillofac Surg. 1977;5(2):118-123.

24. Doepp F, Schreiber SJ, Benndorf G, Radtke A, Gallinat J, Valdueza JM. Venous drainage patterns in a case of pseudotumor cerebri following unilateral radical neck dissection. Acta Otolaryngol. 2003;123(8): 994-997.

25. Weingarten CZ. Simultaneous bilateral radical neck dissection. Preservation of the external jugular vein. Arch Otolaryngol. 1973;97(4): 309-311.

26. Hoyt BJ, Smith R, Smith A, Trites J, Taylor SM. IIb or not IIb: oncologic role of submuscular recess inclusion in selective neck dissections. J Otolaryngol Head Neck Surg. 2008;37(5):689-693.

27. Hui Y, Wong DS, Wong LY, Ho WK, Wei WI. A prospective controlled double-blind trial of great auricular nerve preservation at parotidectomy Am J Surg. 2003;185(6):574-579.
OncoTargets and Therapy

\section{Publish your work in this journal}

OncoTargets and Therapy is an international, peer-reviewed, open access journal focusing on the pathological basis of all cancers, potential targets for therapy and treatment protocols employed to improve the management of cancer patients. The journal also focuses on the impact of management programs and new therapeutic agents and protocols on

\section{Dovepress}

patient perspectives such as quality of life, adherence and satisfaction. The manuscript management system is completely online and includes a very quick and fair peer-review system, which is all easy to use. Visit http://www.dovepress.com/testimonials.php to read real quotes from published authors. 